\title{
Contribuição do design para a alfabetização: uma experiência na criação de um jogo com participação da criança
}

\section{Contribution of design to literacy: an experience in creating a game with child participation}

\section{Laura Caroline Dias Fernandes, Universidade Federal do Rio Grande do Norte lauracarolinedf@gmail.com}

Elizabeth Romani, Universidade Federal do Rio Grande do Norte

elizabeth.romani@ufrn.br

Lorena Gomes Torres de Oliveira, Universidade de Lisboa

lorenagomestorres@gmail.com

\section{Resumo}

Este artigo apresenta e discute uma experiência de criação de um jogo que incentiva o processo de reconhecimento de letras e formação de palavras, destinado a crianças em fase de alfabetização. Para alcançar tal propósito, adotou-se como estrutura simplificada os procedimentos metodológicos de Munari (1998), que foram sistematizados em apenas três fases: definição do problema e coleta de dados; geração de alternativas; e avaliação dos modelos propostos. Ademais, utilizou-se a abordagem do design colaborativo para compreender o interesse e a percepção do público-alvo sobre o artefato projetado. Como resultado, esse processo possibilitou a geração de quatro modelos que foram, posteriormente, avaliados com a participação da criança. Esta investigação pretende contribuir para a discussão sobre métodos de design e processos de alfabetização.

Palavras-chave: Criação, Design colaborativo, Design para criança, Lúdico, Alfabetização.

\begin{abstract}
This article presents and discusses the experience of creating a game that encourages the process of letter recognition and word formation, aimed at children in literacy development. To achieve this purpose, the author adopted the simplified structure of the design methodology proposed by Bruno Munari (1998), which was systematized in only three phases: problem definition and data collection; generation of alternatives; and evaluation of the proposed models. In addition, the collaborative design approach was used to understand the interest and perception of the target audience regarding the designed artifact. As a result, this process enabled the generation of four models that were subsequently evaluated with the child's participation. This investigation aims to contribute to the discussion about design methods and literacy processes.
\end{abstract}

Keywords: Creation, Collaborative design, Design for children, Ludic, Literacy. 


\section{Introdução}

O design para crianças é um campo de pesquisa ainda restrito a poucos núcleos acadêmicos, no entanto, não é uma área recente. Importantes designers se debruçaram em busca de entender as necessidades da criança, tendo como expoente Bruno Munari (1907-1998). É imperativo na atualidade, em que as mídias visuais estão cada vez mais presentes na vida da criança, criar mecanismos de aprendizado que não conflitem com as novas tecnologias, mas que utilizem estruturas semelhantes para atraí-las, como, por exemplo, o jogo educativo. Tendo em vista essa necessidade, esta pesquisa está no limiar entre uma ferramenta de ensino e um brinquedo, acreditando que um artefato lúdico pode ser um caminho para o aprendizado não convencional. Para Broügère (2010, p. 82), a brincadeira é uma atividade que está intimamente relacionada com a cultura, em que a criança se apropria e a transforma da maneira que desejar. Ainda conforme o autor: "A criança se apodera do universo que a rodeia para harmonizá-lo com sua própria dinâmica". Existe, na brincadeira, uma interpretação e uma recodificação adaptada por parte da criança a respeito de tudo o que ela vê e sente do mundo exterior.

De acordo com Kishimoto (1996, p. 24), a brincadeira é "a ação que a criança desempenha ao concretizar as regras do jogo, na ação lúdica”. Já o jogo, segundo a autora, possui uma complexa definição devido à abrangência do ato em cada cultura, em cada faixa etária e contexto: jogo político, jogo de baralho, jogo de bola, entre outros jogos. Para destrinchar suas definições, Broügère (1993) e Henriot (1989 apud KISHIMOTO, 1996) apontam três níveis de diferenciações. $\mathrm{O}$ primeiro deles é que o jogo dependerá do contexto social em que acontece. $\mathrm{O}$ segundo nível seria um sistema de regras, em que permite a diferenciação de cada modalidade por meio de uma sequência de regras, essas guiam o brincar. No terceiro nível, encontra-se o brinquedo, que seria o suporte da brincadeira, o objeto que manipula-se no jogo.

De acordo com Kishimoto (1996), são atribuídas ao jogo ou brinquedo educativo duas funções: a lúdica, em que o jogo diverte e pode gerar prazer ou desprazer, e a função educativa, que ensina algo ao indivíduo que o joga. Dessa maneira, a autora defende que as atividades lúdicas educacionais contribuem para a aprendizagem da criança de muitas formas, desde os seus primeiros meses, em que não há ainda uma consciência do brincar, a criança exercita suas capacidades sensório-motoras, familiariza-se com emoções, aprende a linguagem.

$\mathrm{Na}$ fase escolar, os jogos e brincadeiras contribuem para um melhor desenvolvimento das expressões, contribuem, de acordo com Brougère (2010), para o exercício de socialização, a partir da apropriação de códigos culturais, auxiliam no desenvolvimento da imaginação e da criatividade. Então, ao considerar a necessidade do lúdico no processo de aprendizagem em sala de aula, ressalta-se a importância do design, enquanto área que possibilita a criação e a solução de problemas de materiais mediadores. Segundo Coutinho e Lopes (2011, p. 1), "quando aproximamos o campo do design com o da educação, estamos, de certa forma, arquitetando a construção de uma perspectiva social, centrada na formulação de princípios de design (gráfico e informacional) que possam contribuir com as práticas educacionais".

O contato com as letras e os números começa antes do processo de alfabetização, pois a criança está rodeada de palavras impressas antes de ter a capacidade de codificar os caracteres. Para Vigotsky (2007), o aprendizado de uma criança precede o início da fase escolar, pois ela constrói 
um repertório individual sem a sistematização formal educacional. Ferreiro (2005a) afirma que a linguagem impressa e a oral não são identificadas pela criança de imediato, mas que é importante esse contato antecipado com as letras impressas para o desenvolvimento da alfabetização. Além disso, a autora esclarece que o contexto social é fator relevante para construir uma base sólida para o reconhecimento das letras.

Assim, as práticas sociais e as informações sociais, como os nomes das pessoas e dos objetos que a rodeiam, terão sua assimilação facilitada e podem ser exploradas no momento de aprendizagem. Ainda de acordo com Ferreiro (2005b), a cartilha não funciona quando as frases nela contidas não apresentam relação com a vida da criança. Dessa maneira, grande parte dos manuais e cartilhas, "introduzem sempre um elemento de rigidez na aprendizagem, que dificulta a necessária adaptação às exigências individuais e grupais" (FERREIRO, 2005b, p. 35). Vigotsky (2007) defende que o ensino da leitura e da escrita deve ser organizado de maneira que se tornem necessários à criança, do contrário será uma atividade mecânica e logo a aborrecerá. Assim, a escrita deve ter um significado para as crianças, "uma necessidade intrínseca que deve ser despertada nelas, e a escrita deve ser incorporada a uma tarefa necessária e relevante para a vida" (VIGOTSKY, 2007, p. 144). Logo, compreende-se que a alfabetização deve ser um processo de aprendizado natural, assim como o uso das letras durante uma brincadeira.

Diante da importância do jogo como facilitador no processo de alfabetização não formal, este artigo objetiva discutir os procedimentos de criação de um artefato lúdico e pedagógico que incentive a criança em sua familiarização com as letras do alfabeto e posterior formação de palavras, conforme os princípios defendidos por Vigotsky (2007). Assim, o artefato deverá considerar o contexto social e o repertório da criança na atividade de reconhecimento das letras e formação de palavras e, de igual maneira, possuir uma dinâmica de jogo estimulante. Este trabalho pretende ainda contribuir com o debate sobre procedimento de projeto de design para crianças que possuam uma função informacional, permeando uma breve discussão sobre o reconhecimento e a preferência de diferentes fontes tipográficas. É de se esperar, portanto, que esta pesquisa explore distintos caminhos, tendo em vista o caráter exploratório da investigação e a contribuição do público-alvo em todas as etapas do projeto.

\section{Procedimentos metodológicos}

Para o projeto do jogo foi utilizada como referência a metodologia projetual de Bruno Munari (1998), que aponta doze fases para o projeto de design: Problema, Definição do Problema, Componentes do Problema, Coleta de Dados, Criatividade, Materiais/Tecnologia, Experimentação, Modelos, Verificação, Desenho de Construção, Solução. De acordo com Munari (1998), o método de projeto, para o designer, não é absoluto, nem definitivo, pode ser modificado caso ele encontre outros valores objetivos que melhorem o processo. Dessa forma, o jogo foi desenvolvido em três grandes fases estruturadas nos procedimentos: exploratória, criativa e avaliativa. Além disso, utilizou-se a abordagem do Design Colaborativo, que consiste na dedicação pessoas de

Figura SEQ Figure 1* ARABIC 1: Exemplo de legenda (Times New Roman, corpo mútua de 
conhecimento iguais ou diferentes trabalhando em um mesmo projeto objetivando a busca de soluções de problemas que atendam a necessidade de todos (FONTANA, 2012). Ainda de acordo com a autora (2012, p. 37), "a colaboração visa produzir um produto e/ou serviço consistente e completo através de uma grande variedade de fontes de informação com certo grau de coordenação das várias atividades implementadas”. Essa característica do Design Colaborativo permite, então, não apenas um processo enriquecedor de um projeto como soluções e resultados mais coerentes com a necessidade do usuário final do produto/serviço a ser projetado.

No processo de Design, pensar em alternativas de naturezas diversas, deliberadamente, conserva uma sensação de ambiguidade e incerteza e não se preocupar em chegar a uma solução final tão rapidamente, com se ela fosse única ou correta, são habilidades essenciais (LAWSON, 1990), que vão na mão contrária da tradição do pensamento da escola e que precisam ser estimuladas. Por isso, é importante que as crianças suspendam a desconfiança naquele processo desconhecido, experimentem uma perda de controle em relação ao que já conhecem, e se aventurem nessa aprendizagem sem saber de antemão o que acontecerá ao final (SCHÖN, 2000).

Diante da complexidade de áreas envolvidas na produção de um material lúdico e educativo, esta pesquisa contou com a colaboração de profissionais da área da educação, do design, além de crianças, com idade entre 7 e 10 anos.

\subsection{Etapa exploratória}

Antes de iniciar o projeto do artefato lúdico, foi necessário uma etapa para compreender o problema e seus componentes. Assim, estudou-se os aspectos que envolvem o caráter educativo do objeto e a percepção da criança sobre o mecanismo presente em grande parte dos jogos educativos encontrados no mercado. Para isso, foram realizados revisão de literatura, pesquisa de similares e pesquisa com o público-alvo. Ferreiro (2005), Soares (2011) e Vigotsky (2007) foram autores relevantes para fundamentar os componentes do problema, uma vez que permitiram esclarecer a aplicação dos conceitos de "lúdico" e "alfabetização". Após compreender as especificidades do problema, buscou-se projetos e brinquedos que apresentassem propostas similares, utilizando para isso uma plataforma de busca na internet. Os exemplos coletados foram sistematizados em um quadro, elencando os aspectos positivos e negativos de cada proposta. Nesse momento, o quadro síntese de similares foi apresentado para quatro professoras do ensino básico do Núcleo de Educação da Infância (NEI) com intuito de promover uma discussão coletiva sobre jogos educativos e tipografia para crianças. Por último, foi desenvolvida uma atividade de inspiração com a participação de duas crianças do gênero masculino, denominadas para efeito de pesquisa e para preservar a identidade, como Participante A (7 anos) e Participante B (10 anos), com o objetivo de coletar a opinião da criança sobre o processo não formal de reconhecimento de letras. A dinâmica teve uma hora de duração para livre exploração de ideias, sem a intervenção das pesquisadoras e com a participação da mãe das crianças. Para a atividade, foram disponibilizados diversos materiais (papéis coloridos, tesoura, cola, massinha de modelar, E.V.A. 
colorido, carimbeira). Após explicar a proposta da atividade, foram concedidos 30 minutos para formulação de ideias. Ao final, foi solicitado às crianças que explicassem a proposta.

\subsection{Etapa criativa}

Os dados sistematizados na etapa anterior, análise de similares e atividade com o Participante A e B, serviram de ponto de partida para a fase de geração de ideias. Além das informações coletadas com o público-alvo, foram considerados os conceitos explorados pelas crianças em um brainstorming. Os esboços foram organizados por similaridade e selecionou-se duas ideias para a construção de modelos em materiais de baixo valor de custo, tais como papel, papelão e material emborrachado (E.V.A.). Cabe salientar que o desenvolvimento dos modelos (Figuras 1 e 2) se deu ao longo das avaliações com as crianças, de maneira que a reflexão sobre a opinião do público-alvo proporcionasse melhorias no projeto. Para a construção dos modelos foram utilizadas técnicas manuais de corte como premissa para viabilizar a produção, uma vez que as pesquisadoras não dispunham do acesso aos equipamentos de fabricação digital e de marcenaria. Ademais, foi estabelecido como premissa de projeto os mecanismos lúdicos: montagem de letras e carimbos. A montagem de peças em material emborrachado e impressão por meio de carimbos teve o propósito de desenvolver o estímulo para composição de letras e, posteriormente, formar palavras a partir do repertório da criança, conforme estratégia defendida por Ferreiro (2005) e Soares (2011).
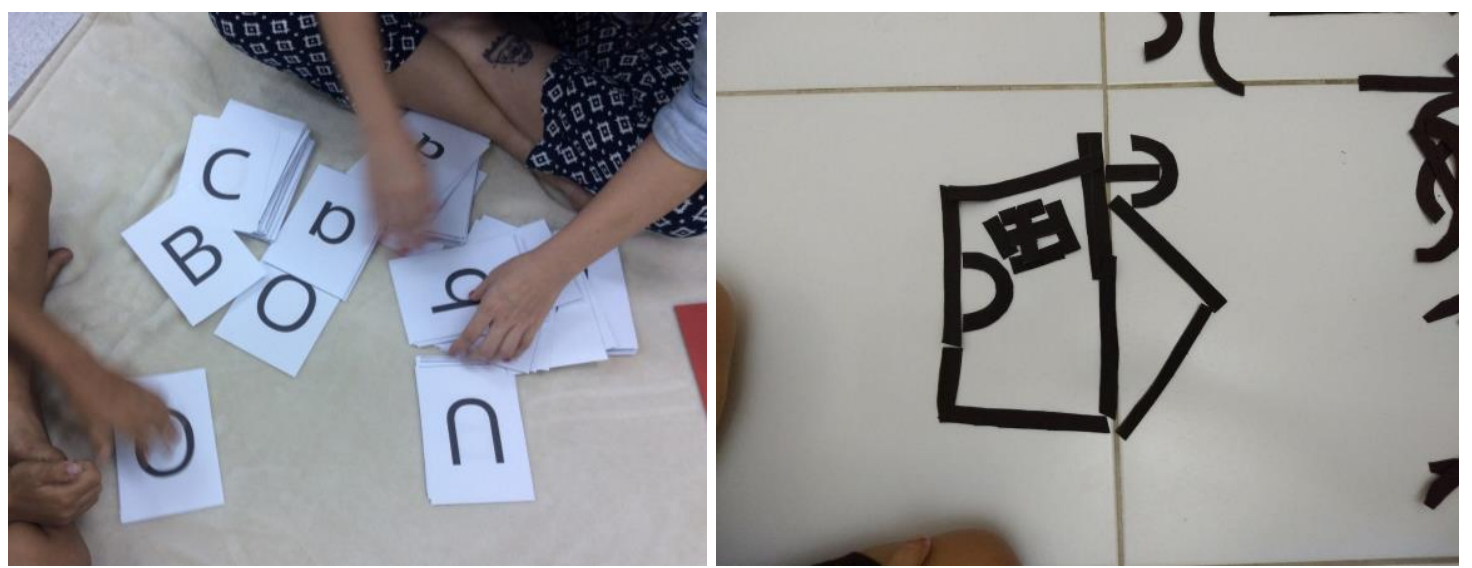

Figura 1: modelo 1 (esquerda) e modelo 2 (direita).

Fonte: Acervo das autoras. 

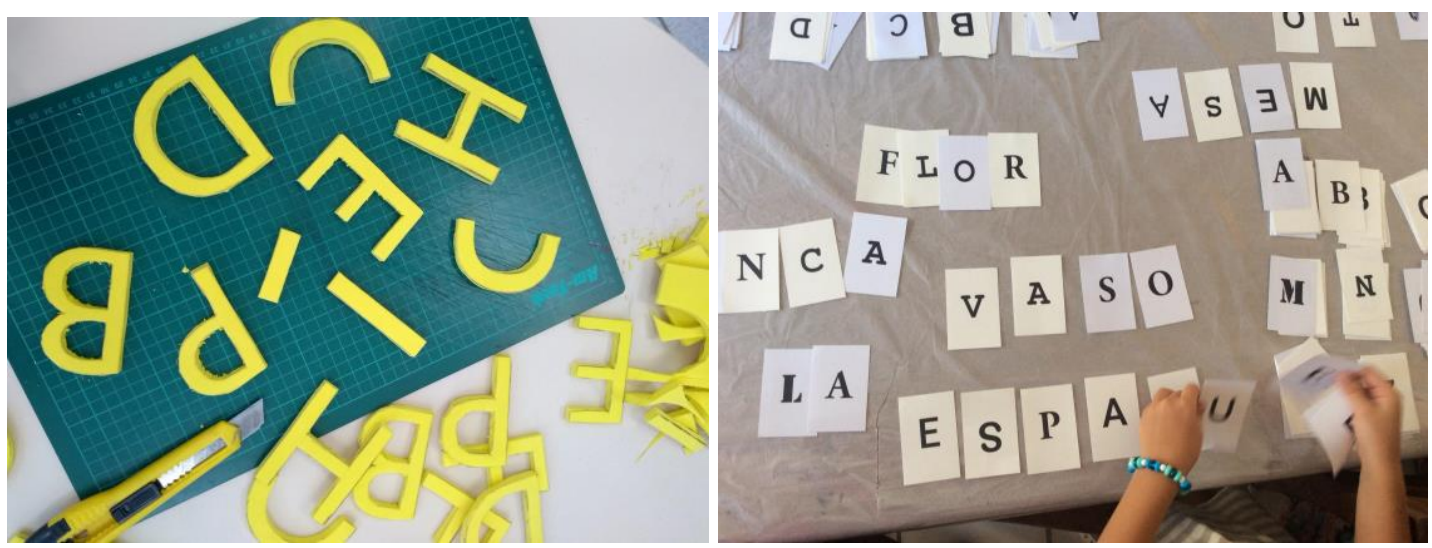

Figura 2: modelo 3 (esquerda) e modelo 4 (direita).

Fonte: Acervo das autoras.

\subsection{Etapa avaliativa}

A avaliação com o público-alvo é uma etapa necessária em projetos de design, pois é momento em que se avalia possíveis erros na solução proposta. A verificação dos modelos propostos com as crianças teve três momentos com grupos distintos, o primeiro contou com a colaboração de uma criança do gênero masculino, denominado Participante $\mathrm{C}$ ( 7 anos), o segundo momento contou com as duas crianças, Participantes A e B, que colaboraram antes da fase exploratória, e o terceiro momento o artefato foi avaliado com a participação de sete crianças, com idade entre 7 e 10 anos, sendo duas do gênero feminino e quatro do gênero masculino. Por envolver a participação de seres humanos, o projeto foi submetido e aprovado pelo Comitê de Ética em Pesquisa (CAAE - Universidade Federal do Rio Grande do Norte). A primeira avaliação teve duração de 50 minutos com participação das pesquisadoras como mediadoras durante a interação da criança com os artefatos propostos (Modelo 1 e Modelo 2). Já na segunda avaliação, foi aplicada a técnica da observação não participativa para analisar outra proposição de artefato lúdico (Modelo 3), sendo apenas explicado às crianças a dinâmica da atividade proposta. Assim, foram concedidos 50 minutos para criação livre. Após a análise qualitativa das informações levantadas nas etapas anteriores e a sistematização dos resultados, foi realizada uma nova proposta de jogo (Modelo 4). De igual maneira aos procedimentos de avaliação adotados nos modelos anteriores, o modelo 4 foi avaliado com a participação de sete crianças. Em todos os processos de avaliação com as crianças foram realizados registros fotográficos para verificação dos dados com o consentimento dos responsáveis legais que acompanharam a atividade como observadores não participativos.

\section{Resultados e discussão}

O projeto iniciou, conforme relatado nos procedimentos metodológicos, com o levantamento de informações para a construção do artefato. Para a pesquisa de similares, foram investigadas 
propostas de jogos que apresentassem a dinâmica para a formação de letras ou palavras. Para o levantamento desses jogos, utilizou-se o repertório dos colaboradores da pesquisa e a internet com as seguintes palavras-chave: "jogo", "alfabetização" e "construção de palavras". Após a seleção dos projetos, eles foram organizados em painéis de referências de acordo com a similaridade da proposta lúdica.

Após o levantamento de similares, as pesquisadoras fizeram uma breve análise descrevendo os pontos positivos e negativos de cada jogo. A apresentação dessa análise foi exposta aos professores do Núcleo de Educação da Infância da Universidade Federal do Rio Grande no Norte (NEI-UFRN) (colaboradores do projeto) para que emitissem suas opiniões a respeito dos jogos selecionados. A partir da discussão, concluiu-se que o elemento surpresa poderia ser um partido de projeto. Ao ponderar a relevância educacional para a criança, determinou-se como premissa de projeto que a dinâmica do jogo também deverá contemplar a criação de palavras ao invés da formação de letras isoladas. As educadoras também salientaram que as crianças em fase de alfabetização, em geral, tomam contato com as fontes em caixa alta antes da caixa baixa, tanto em sala de aula como em livros. Além disso, discutiu-se a necessidade de ser um produto com emprego de materiais de baixo custo, tendo em vista a restrição orçamentária de escolas públicas e a possível reprodução seriada para uso em sala de aula.

$\mathrm{Na}$ sequência, identificou-se a necessidade de coletar a opinião do público-alvo sobre caminhos possíveis para a promoção da alfabetização não formal. Para tal, convidou-se duas crianças, Participante A (7 anos) e Participante B (10 anos), para uma atividade de geração de ideias. Antes de iniciar a prática, explicou-se para as crianças os objetivos da pesquisa e apresentou-se os materiais disponíveis (papéis coloridos, tesoura, cola, lápis, E.V.A. colorido e massinha de modelar). Depois foram concedidos 45 minutos para o processo de criação e execução, sendo solicitado que elas pensassem em uma atividade, brincadeira ou jogo que, na opinião delas, auxiliasse outras crianças na aprendizagem da leitura e da escrita.

O Participante B propôs um livro de atividades para facilitar o processo de leitura das letras por meio de palavras e imagens associativas, com a regra que a letra comanda o início da palavra, como, por exemplo, "a" com "abelha". De acordo com o Participante B, o livro poderia ser utilizado tanto por uma única criança ou em conjunto com outras. A interação proposta se resume à leitura das palavras, indicando um processo semelhante ao de uma cartilha tradicional. Durante a explicação do funcionamento da proposta, observou-se que o projeto não despertou muito interesse do público-alvo, representado pelo Participante A.

Já o Participante A modelou todas as letras do alfabeto com a massinha oferecida, utilizando uma cor a cada duas letras. Ele propôs um exercício de produzir letras em que outras crianças pudessem participar. Relatou que a atividade deveria ser instruída no começo e livre depois. A responsável pelas crianças, que também participou da sessão de geração de ideias, propôs um kit de papéis coloridos em que cada participante pudesse recortar as letras. Ela explicou que, em um segundo momento, em grupo, as letras produzidas seriam colocadas juntas para montar uma composição. O desafio proposto seria a formação de palavras com letras de diferentes estilos. 

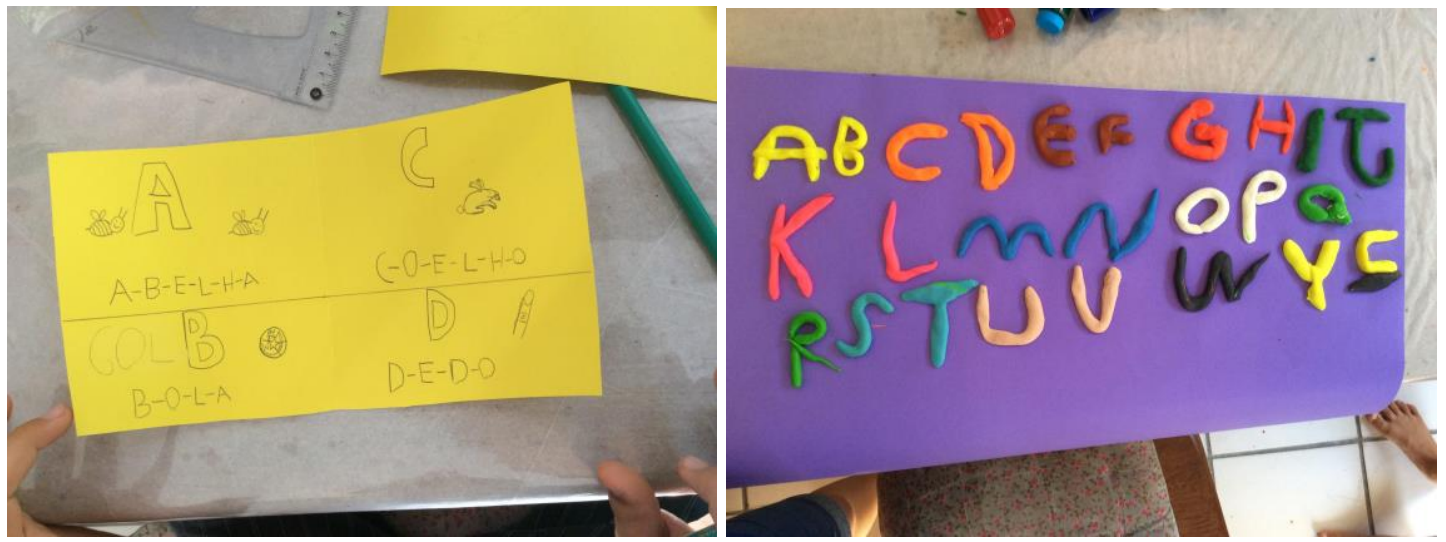

Figura 3: Exercício proposto pelo Participante B (esquerda) e pelo Participante A (direita). Fonte: Acervo das autoras.

Ao final da atividade de geração de ideias, foram avaliados alguns pontos importantes para o desenvolvimento do artefato lúdico. Assim, foram elencados os critérios mais relevantes durante a pesquisa: dinâmica em grupo, utilização de cores variadas e criação de letra pela criança. Cabe salientar que o Participante $\mathrm{B}$, sendo mais velho, não conseguiu dissociar a alfabetização dos processos escolares conhecidos.

$\mathrm{Na}$ etapa seguinte, foram esboçados alguns modelos adotando as seguintes diretrizes: emprego de materiais de baixo custo, em decorrência da produção, e técnicas manuais de produção. Assim, foram elaboradas propostas de desmembramento de letras em material emborrachado (E.V.A.) em diferentes espessuras e cartelas com letras impressas com famílias tipográficas diversas. Os modelos estudados e executados nessa fase foram posteriormente avaliados por crianças, com objetivo de analisar a familiaridade do público-alvo com a tipografia, observando a percepção delas com relação a diferentes famílias tipográficas (com e sem serifa) e versões (caixa alta e caixa baixa). Além disso, exploraram-se nos modelos duas fontes cursivas. Durante a dinâmica com as crianças, foi possível observar equívocos e acertos que nos auxiliaram nas fases posteriores.

A avaliação contou com uma criança de 7 anos (Participante C), acompanhada de seu responsável. Os materiais utilizados na atividade foram: livros para crianças, cartelas de papel ofício tamanho A6 (319 x $201 \mathrm{~mm})$ com letras impressas em tinta preta e uma primeira proposta com peças oriundas de fragmentos de letras. A proposta de letras modulares (modelo 2) foi produzida em material emborrachado preto (E.V.A.), de espessura de $1,5 \mathrm{~cm}$ e de altura máxima de $10 \mathrm{~cm}$, na qual foram cortadas com o auxílio de um estilete. As formas foram pensadas de maneira que a junção das peças pudesse formar letras. Já as tipografias impressas nas cartelas (modelo 1), foram escolhidas a partir de uma pesquisa geral de fontes mais adequadas para o ensino e legibilidade para crianças. Muitas das famílias tipográficas apontadas na pesquisa como ideais para a criança são fontes pagas. Por isso, procurou-se fontes open source oferecidas pelo serviço Google Fonts, selecionando famílias que tivessem o desenho da face do tipo o mais semelhante possível do apontado nas pesquisas. Assim, foram selecionadas as seguintes fontes: Open Sans, Muli, Sacramento, Times New Roman. Além disso, foram impressos caracteres criados por uma das pesquisadoras, semelhante à letra manuscrita. 
A atividade avaliativa foi realizada no Departamento de Artes da UFRN. Após as apresentações e a leitura dos protocolos de pesquisa, foi realizada uma leitura mediada de um livro com o intuito de provocar o olhar do Participante $\mathrm{C}$ para a tipografia diferente presente na narrativa. Depois, as cartelas com diferentes letras foram embaralhadas e distribuídas pelo chão e solicitou-se para que ele agrupasse as letras em grupos alfabéticos. Neste momento, observou-se que o número de cartelas, e consequentemente de tipografias, estava em uma quantidade superior ao que a criança teria capacidade de identificar e separar no limite de tempo previamente planejado. Assim, foi estipulado no máximo 50 minutos para toda a atividade, levando em consideração o tempo limite de concentração de uma criança para uma determinada atividade. $\mathrm{O}$ excesso de cartelas resultou, por consequência, no encerramento da atividade antes de seu término e no desinteresse do participante pelo exercício.

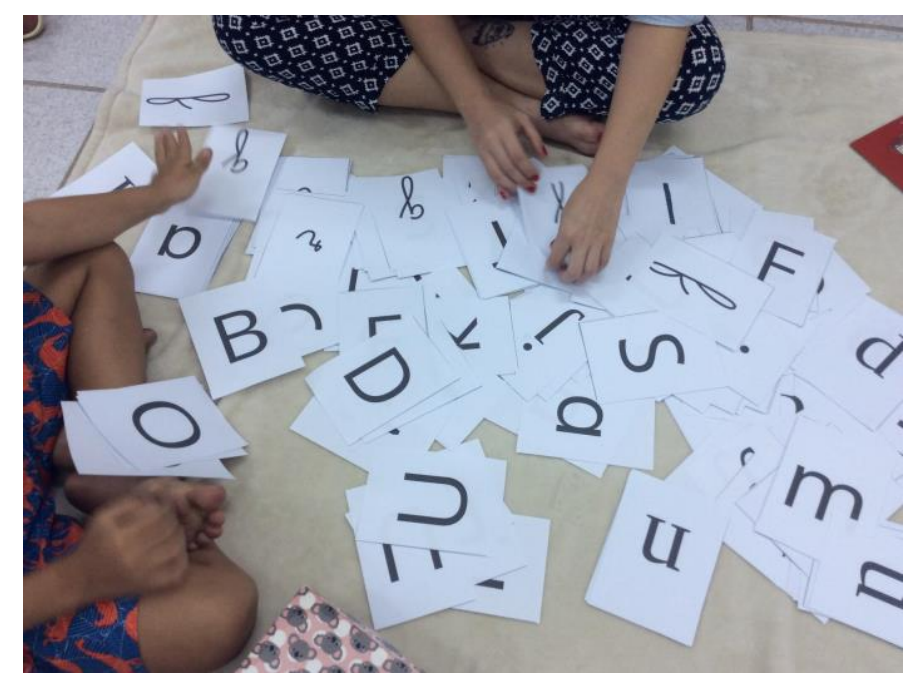

Figura 4: Participante $\mathrm{C}$ identifica as letras impressas em cartelas.

Fonte: Acervo das autoras.

Em relação à tipografia, foi possível coletar uma série de observações e reações de Participante $\mathrm{C}$ diante da descoberta dos diferentes desenhos da face. O primeiro deles foi em relação à fonte cursiva (Sacramento), em que ele não identificou os caracteres e descreveu as letras como sendo apenas rabiscos. As letras " $u$ " e " $n$ " minúsculas da fonte sem serifa (Open Sans) foram confundidas e colocadas na mesma pilha de cartelas, assim como ocorreu com a letra minúscula sem serifa "l" e a letra sem serifa maiúscula "i", a letra sem serifa maiúscula "M" e "W", as letras sem serifa e minúsculas "i” e "j”. Ele também relatou a preferência por fontes caixa alta e sem serifa, alegando ter mais facilidade de reconhecer a letra.

Por último, o Participante $\mathrm{C}$ foi convidado a brincar com as peças emborrachadas. Um dos objetivos, nessa proposta, era o de avaliar se a criança teria a iniciativa de construir letras ou nomes com o material fornecido. Após algum momento examinando-as, ele decidiu formar primeiramente desenhos com as peças e, logo após, com o incentivo da pesquisadora e do responsável, construiu com as peças a palavra "ovov". 


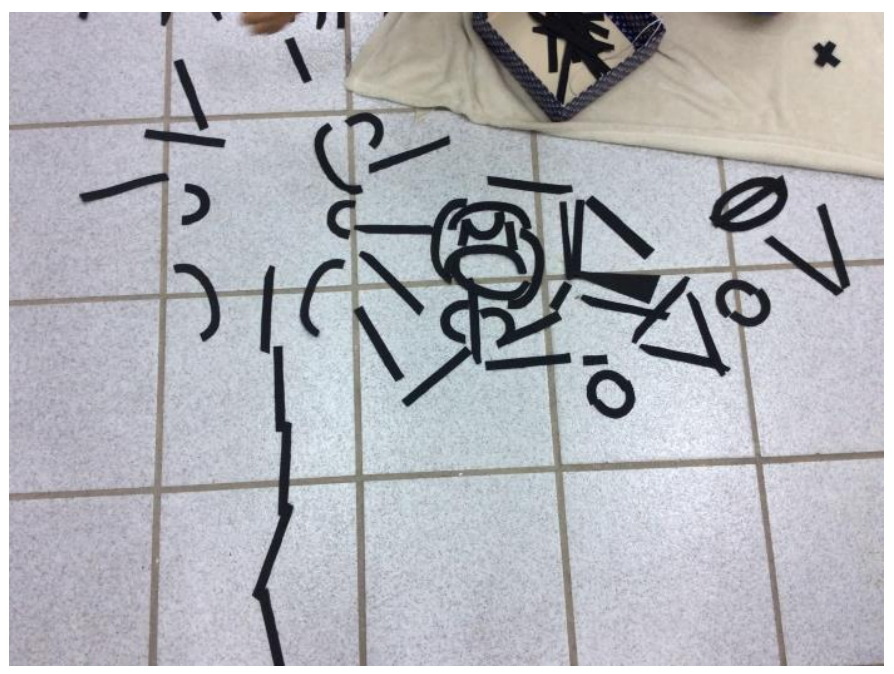

Figura 5: Participante $\mathrm{C}$ monta desenhos e letras com modelo 2.

Fonte: Acervo das autoras.

Após a análise da primeira avaliação, as pesquisadoras propuseram alguns ajustes no modelo inicial e foi realizada uma segunda dinâmica para avaliação de novas peças. Nesse momento, o Participante A e o Participante B foram convidados novamente para analisar a proposta. O modelo 3 foi construído em E.V.A. a partir de um conjunto de fragmentos de letras, como o modelo anterior, e algumas letras inteiras. Optou-se por deixar mais as letras com uma espessura maior. Outra alteração significativa na atividade, foi a proposta de usar as peças como carimbos ao invés de apenas montá-las. As letras representadas inteiras nas peças da atividade foram escolhidas de modo aleatório, ao todo foram 10 letras que contavam com B, C, D, E, F, H, L, N, T, P e a fonte utilizada foi a Myriad Pro, devido a sua forma simples e arredondada.

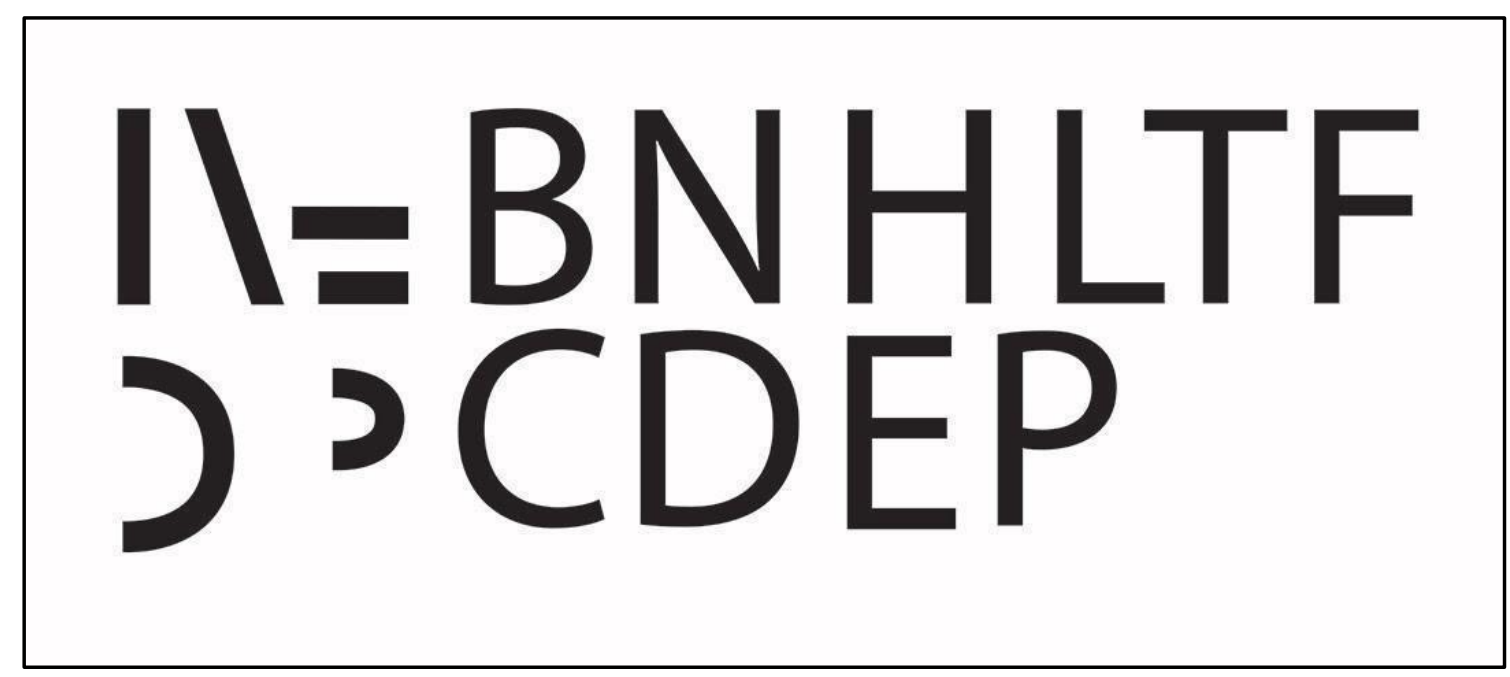

Figura 6: Esquema de formas e letras utilizadas na construção do modelo 3.

Fonte: Acervo das autoras.

Durante a avaliação do modelo 3, o Participante B se animou com os fragmentos de letras e sem qualquer intervenção mediada começou a montar as letras para construir as palavras, demonstrando muito interesse na atividade. O Participante A tentou carimbar as iniciais do nome, 
com duas letras já prontas, porém, ao perceber que não havia todas as letras do alfabeto, perdeu o interesse na atividade. Depois de um tempo, ele foi incentivado pela sua responsável a continuar montando as demais letras, mas logo se frustrou ao perceber que não conseguiria montar a letra " $\mathrm{R}$ " da maneira que imaginava.

Observou-se em ambos os participantes certa insatisfação com a técnica de carimbo, pois não permitia a construção de uma letra perfeitamente delineada, além disso, o Participante B apontou como um fator negativo a falta de rigidez das peças, alegando que essa característica dificultou a execução da atividade. Dessa maneira, a técnica do carimbo, que inicialmente parecia uma solução interessante para a ludicidade da atividade, mostrou-se inadequada para os fins propostos.

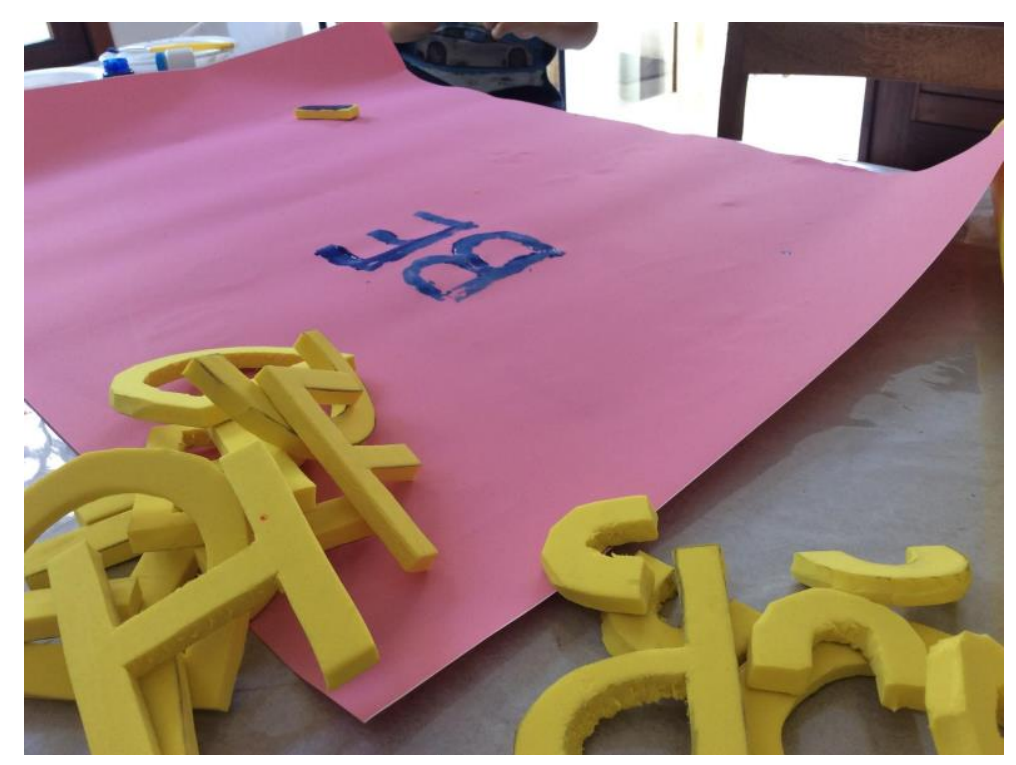

Figura 7: Participante B carimba as iniciais do nome.

Fonte: Acervo das autoras.

A partir das avaliações realizadas, foi projetada uma nova versão de modelo, com possibilidade de criação de um jogo fundamentado na composição de palavras com diferentes tipos de letras impressas em cartelas, retomando o primeiro modelo com os ajustes. Na nova versão, modelo 4, foram inseridas seis cartelas com ilustrações de cenas do cotidiano de uma criança e representadas de maneira fantasiosa. As ilustrações foram criadas e ilustradas por uma das pesquisadoras exclusivamente para o jogo (Figura 8). As fontes foram escolhidas seguindo os critérios: uso de caixa alta, letra centralizada na cartela, variedade de desenho da face. Assim, foram utilizadas as fontes Courier New, Folio Medium, Garamond, Rosewood std, Stencil, Tekton Pro e Arial Rounded, evitando-se as fontes que não permitiam uma rápida identificação das letras pelas crianças. 


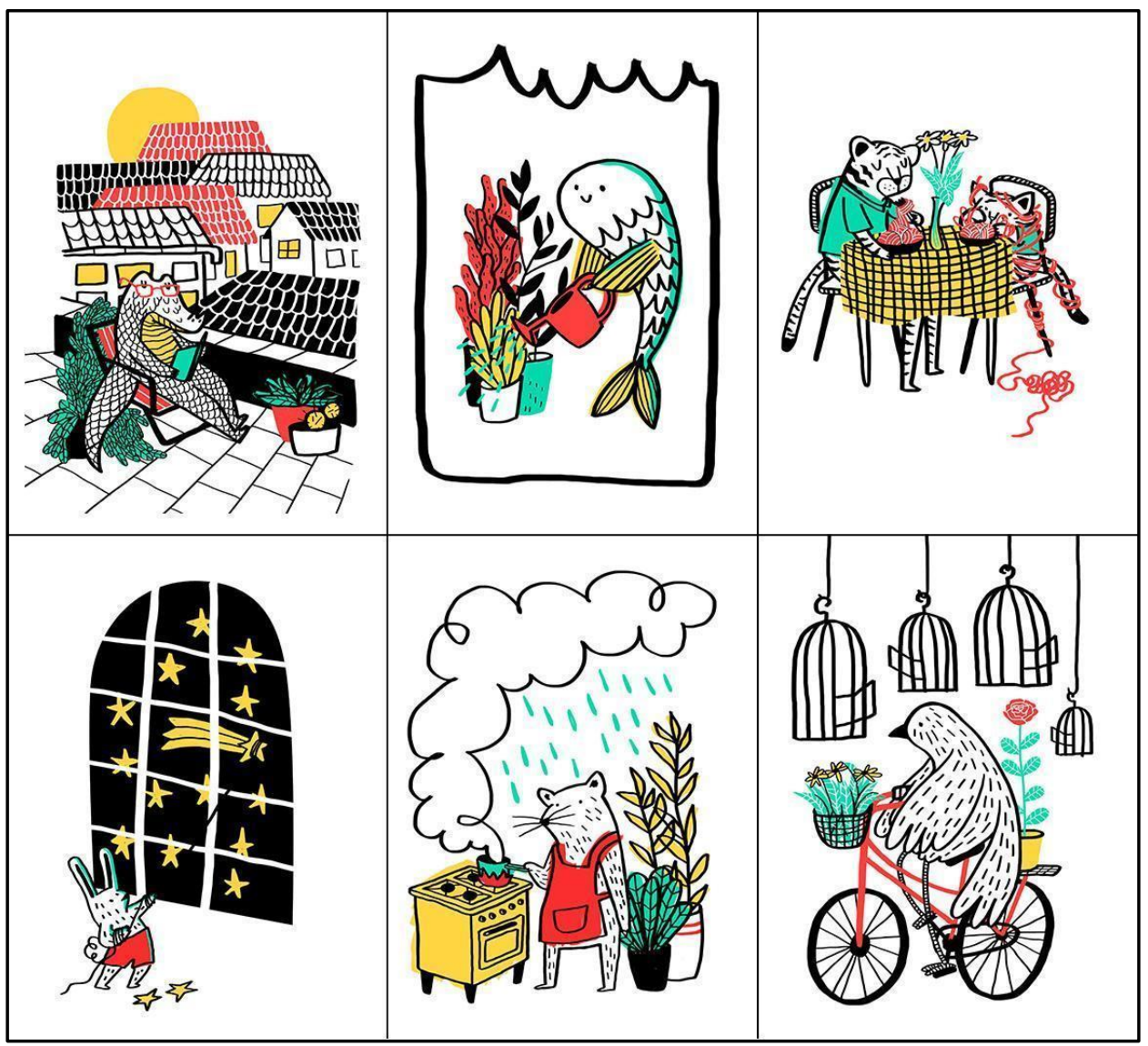

Figura 8: ilustrações que estamparam as cartelas do jogo.

Fonte: Acervo das autoras.

Para o modelo 4, determinou-se que a regra central do jogo fosse a montagem de palavras com as cartelas de letras a partir da observação das cartelas ilustradas (Figura 9). Notou-se a partir de avaliações anteriores, que as crianças precisam de desafios para serem estimuladas, assim estabeleceu-se um tempo de duração para formação das palavras e um sistema de pontuação por quantidade de letras utilizadas na montagem das palavras. A avaliação do jogo foi realizada com as duas crianças da avaliação anterior, Participantes A e B, e mais outras três crianças de 6 a 10 anos. Para a atividade, os participantes foram separados em dois grupos e estabeleceram-se 5 minutos para a criação de palavras a partir de cada cartela ilustrada. 


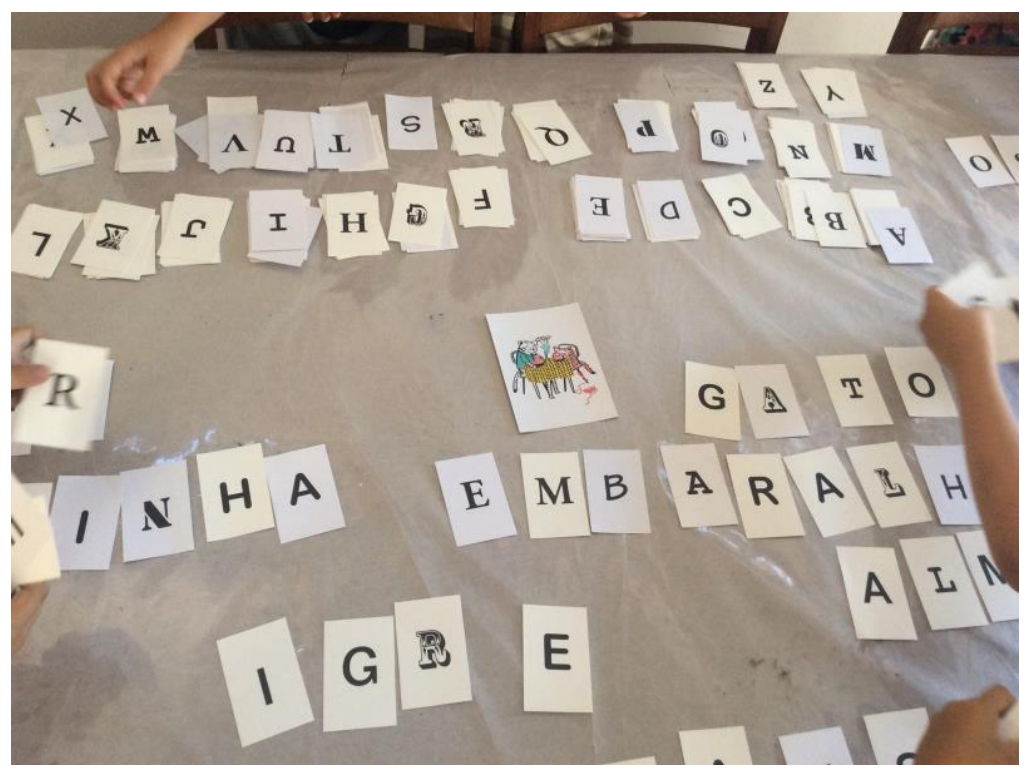

Figura 9: Participantes constroem palavras a partir dos elementos identificados na cartela ilustrada.

Fonte: Acervo das autoras.

Ao final de 8 rodadas, perguntou-se às crianças qual a opinião delas em relação ao jogo. Elas afirmaram terem gostado da experiência e foi apontado por uma das crianças a necessidade da inclusão dos diacríticos para construção plena das palavras. A partir da avaliação do modelo 4, as pesquisadoras observaram a necessidade de redução da quantidade de letras utilizadas por grupo/participante, ou até mesmo a possibilidade de elas estarem previamente organizadas por ordem alfabética. As diferentes tipografias presentes nas cartelas não despertaram muito interesse nas crianças, notou-se que elas as utilizaram de maneira livre sem pensar no desenho da face.

Observou-se ainda que as cartelas ilustradas funcionaram como incentivo no processo de composição de palavras no lugar de manter apenas o repertório de nomes, com o qual a criança já está familiarizada. Os desenhos com um viés fantástico facilitaram o envolvimento delas no jogo. No entanto, o tamanho da cartela ilustrada mostrou-se inadequado para a dinâmica com mais de 2 participantes. Em metade das rodadas, propôs-se a montagem das palavras a partir da mesma ilustração, observando-se o aumento da competitividade entre os grupos. Disso, constatou-se que, quanto maior a competitividade no jogo, maior foi o interesse da criança e maior o seu envolvimento na atividade.

\section{Considerações finais}

A pesquisa de criação e avaliação de artefato lúdico que auxilie o processo de alfabetização, utilizando ferramentas do design colaborativo, resultou na elaboração de uma proposta de jogo composto de cartelas impressas. As crianças participantes desenvolveram competências em relação à autonomia e ao protagonismo. Além disso, as atividades realizadas juntamente com os 
pedagogos durante o processo de crição foram fundamentais para entender quais mecanismos se mostraram mais estimulante para a montagem de palavras.

A construção de modelos diferentes permitiu levantar algumas observações de estratégias para a construção do artefato. A respeito disso, diagnosticou-se, durante as dinâmicas de avaliação, que os processos de construção de palavras que demandaram mais tempo e concentração foram os que mais desestimularam as crianças, a exemplo do carimbo e da separação das cartelas por grupos alfabéticos.

Todas as atividades executadas com a participação de diferentes crianças possibilitaram confrontar gostos pessoais e convergir pontos comuns entre elas. No entanto, o modelo final precisa ainda ser ajustado e validado com uma quantidade maior de participantes. Assim, esperase que, após a validação com outras crianças, o modelo possa ser reproduzido em escala e utilizado em sala de aula como ferramenta de incentivo ao reconhecimento de letras e composição de palavras.

Esta investigação contribuiu com a discussão sobre os métodos de design e processos de alfabetização para desenvolver um jogo educativo com a participação da criança. No entanto, a pesquisa e a construção de um modelo refinado não se esgotam aqui, pois julga-se necessário avaliar o protótipo com crianças de diferentes repertórios. Por fim, almeja-se que os procedimentos metodológicos descritos possam contribuir com a discussão de pesquisas sobre métodos de design e processos de alfabetização.

\section{Referências}

BROÜGÈRE, Gilles. Jogo e educação. Trad. Patrícia Chittoni Ramos. Porto Alegre: Artes Médicas, 1998.

BROÜGÈRE, Gilles. Brinquedos e companhia. Trad. Maria Alice Sampaio Doria. São Paulo: Cortez, 2004.

LOPES, C. E. Os desafios para educação estatística no currículo de matemática. In: LOPES, C. E.; COUTINHO, C. de Q. e S.; ALMOUlOUD, S. A. (org.) Estudos e reflexões em educação estatística. Campinas: Mercado de Letras, 2010.

FERREIRO, Emilia. Alfabetização em processo. Trad. Sara Cunha Lima. São Paulo: Cortez, 2005a.

FERREIRO, Emilia. Com todas as letras. Trad. Maria Zilda da Cunha Lopes. São Paulo: Cortez, 2005b.

FONTANA, Cleide Madalena. A importância da psicomotricidade na educação infantil. 2012. 78 p. Monografia (Especialização em Educação: Métodos e Técnicas de Ensino) Universidade Tecnológica Federal do Paraná, Medianeira, 2012.

KISHIMOTO, Tizuko Morchida (org.). Jogo, brinquedo, brincadeira e a educação. São Paulo: Cortez, 2007. 
KISHIMOTO, Tizuko Morchida (org.). O brincar e suas teorias. São Paulo: Cengage Learning, 2010.

LAWSON, Alexander S. Anatomy of a Typeface. Boston: David R Godine, 1990.

MUNARI, Bruno. Artista e designer. Portugal: edições 70, 2001.

MUNARI, Bruno. Das coisas nascem coisas. São Paulo: Martins Fontes, 1998.

MUNARI, Bruno. Design e comunicação visual: contribuição para uma metodologia didática. São Paulo: Martins Fontes, 1997.

MUNARI, Bruno. I laboratori tattili: a cura di Bruno Munari. Itália: Zanichelli, 1985.

MUNARI, Bruno. Fantasia. Lisboa: Edições 70, 2007.

SCHÖN, D. A. Educando o profissional reflexivo: um novo design para ensino e a aprendizagem. Trad. Roberto Cataldo Costa. Porto Alegre: Artes Médicas Sul, 2000.

SOARES, Magda. Alfabetização e letramento. 6. ed. São Paulo: Contexto, 2011.

SOARES, Magda. Letramento e alfabetização: as muitas facetas. In: REUNIÃO ANUAL DA ANPED, 26., 2003, Poços de Caldas. Revista Brasileira de Educação. Poços de Caldas, MG: Universidade Federal de Minas Gerais, 2003. (GT Alfabetização, leitura e escrita).

VIGOTSKY, Lev. A formação social da mente. São Paulo: Martins Fontes, 2007.

\section{Sobre as autoras}

\section{Laura Caroline Dias Fernandes}

Possui graduação em Design pela UFRN e especialização em Comunicação, Marcas e Consumo pela UnP. Trabalha com design de superfície na área de moda.

ORCID: 0000-0002-3327-4353

\section{Elizabeth Romani}

Possui graduação em Arquitetura e Urbanismo, mestrado e doutorado pela FAU USP. É professora adjunta do Departamento de Design da Universidade Federal do Rio Grande do Norte e do Programa de Pós-graduação em Educação Especial. Tem experiência na área de design gráfico e suas pesquisas atuais reúnem os seguintes temas: desenho universal, acessibilidade comunicacional, design para criança e processos gráficos.

ORCID: 0000-0002-4627-562X

\section{Lorena Gomes Torres de Oliveira}

Possui graduação em Design pela UFRN, graduação em Arquitetura e Urbanismo pela UnP e pelo IFRN é Tecnóloga em Produção da Construção Civil. Na UFPE realizou seus estudos de mestrado na área de Design. Foi professora temporária de Design da UFRN. É professora da UnP nos cursos de Design Gráfico e Design de Moda. Doutoranda em Design pela Universidade de Lisboa, investiga as relações entre o design, decolonialismo e ensino.

ORCID: 0000-0003-4490-4944 